\title{
Magnitude and frequency of heat and cold waves in recent decades: the case of South America
}

\author{
Guido Ceccherini $^{1}$, Simone Russo $^{2}$, Iban Ameztoy ${ }^{1}$, Claudia Patricia Romero ${ }^{3}$, and Cesar Carmona-Moreno ${ }^{1}$ \\ ${ }^{1}$ European Commission, Joint Research Centre (JRC), Institute for Environment and Sustainability (IES), Water Unit, \\ Via E. Fermi 2749, 21027 Ispra, Italy \\ ${ }^{2}$ European Commission, Joint Research Centre (JRC), Institute for the Protection and Security of the Citizen (IPSC), \\ Financial and Economic Analysis Unit, Via E. Fermi 2749, 21027 Ispra, Italy \\ ${ }^{3}$ Facultad de Ingeniería Ambiental, Universidad Santo Tomás, 5878797 Bogota, Colombia
}

Correspondence to: Cesar Carmona-Moreno (cesar.carmona-moreno@jrc.ec.europa.eu)

Received: 12 November 2015 - Published in Nat. Hazards Earth Syst. Sci. Discuss.: 10 December 2015

Revised: 14 March 2016 - Accepted: 15 March 2016 - Published: 21 March 2016

\begin{abstract}
In recent decades there has been an increase in magnitude and occurrence of heat waves and a decrease of cold waves, both of which may be related to the anthropogenic influence. This study describes the extreme temperature regime of heat waves and cold waves across South America over recent years (1980-2014). Temperature records come from the Global Surface Summary of the Day (GSOD), a climatological data set produced by the National Climatic Data Center that provides records of daily maximum and minimum temperatures acquired worldwide. The magnitude of heat waves and cold waves for each GSOD station are quantified on an annual basis by means of the Heat Wave Magnitude Index and the Cold Wave Magnitude Index. Results indicate an increase in intensity and in frequency of heat waves, especially in the last 10 years. Conversely, no significant changes are detected for cold waves. In addition, the trend of the annual temperature range (i.e. yearly mean of $T_{\max }$ - yearly mean of $T_{\min }$ ) is positive - up to $1{ }^{\circ} \mathrm{C}$ per decade - over the extratropics and negative - up to $0.5^{\circ} \mathrm{C}$ per decade - over the tropics.
\end{abstract}

\section{Introduction}

In the coming decades, climate change will expose hundreds of millions of people to its impacts (Pachauri et al., 2014; Solomon et al., 2007; WHO, 2015). Many areas of the world - Africa and Latin America, among others (Niang et al., 2014) - will have to deal with increases in temperature and changes in extreme weather conditions such as heat waves, altering the probability of experiencing major heat waves in the very near future (Field et al., 2012). This, in turn, may lead to serious implications, mainly health and health-service related (Barnett et al., 2012; Conti et al., 2005; Ostro et al., 2009). The 2003 European heat wave (Beniston, 2004) illustrated how infrastructures, even in highly developed countries, can fail to deal with such environmental challenges.

From this perspective, variability and changes in extreme temperature regimes present a considerable challenge for South America (Magrin et al., 2014). Different aspects of the occurrence of temperature extremes - both spatially and temporally - are still lacking for the continent (Rusticucci, 2012). A complete picture, along with a robust assessment, of temperature extreme regimes might provide essential information on the climate-related risks that society now face, and how these risks are changing.

Amongst the areas of South America most vulnerable to heat and cold waves are the so-called "megacities", i.e. metropolitan areas with total populations in excess of 10 million people such as Bogota, Sao Paulo, Rio de Janeiro, and Buenos Aires. Climate change issues are thus coupled with anthropic pressure issues.

In order to study extreme temperature regimes, daily records are needed. This requirement is particularly hard to meet in South America, which has a sparse sensing network. To overcome this problem, the Global Surface Summary of the Day (GSOD) meteorological data set has been employed. GSOD is a compilation of daily meteorological data pro- 
duced by the National Climatic Data Center (NCDC), available from 1929 to present, which displays a reasonably dense coverage across South America. GSOD has been recently employed to show an increase in the number of heat waves in urban areas at the global scale (Mishra et al., 2015).

The aim of this paper is twofold. Firstly, we calculate annual magnitudes of heat waves and cold waves during 1980 2014 using maximum and minimum daily temperature from GSOD meteorological records. Secondly, we estimate trends of maximum, minimum temperature, and their relative range across South America. These analyses put in evidence of different aspects of temperature extremes, still largely unknown across South America.

The analysis presented below follows a three-step procedure that is divided as follows: (1) selection of temperature records with at least 30 years of data (see Sect. 2.2.1); (2) calculation of the Heat Wave Magnitude Index (HWMI) and Cold Wave Magnitude Index (CWMI) for the period 1980-2014; (3) estimation of the trend for annual mean of daily maximum temperature, annual mean of daily minimum temperature, and the mean temperature range (i.e. MTR $=$ annual mean of daily maximum - annual mean of daily minimum temperature; see Sect. 2.2 for further details).

\section{Materials and methods}

\subsection{Materials: GSOD}

GSOD is a product produced by the NCDC, derived from synoptic/hourly observations. GSOD records are mainly collected at international airports. GSOD records include mean, maximum, and minimum values of temperature, dew point, sea level and station atmospheric pressures, visibility, and wind speed including maximum sustained wind speed and/or wind gusts, precipitation amounts, snow depth, and indicators for occurrences of various weather elements such as fog, rain, snow, hail, thunder, and tornado. Historical data are generally available from 1929, with data from 1973 onwards being the most complete. The total number of GSOD stations available across South America is equal to 912. However, not all of them satisfy the condition of having at least a 30-year timespan, as needed to calculate heat and cold wave magnitude indices, as described in Sect. 2.2.

\subsection{Methods}

GSOD data are quality controlled through automated quality checks. Most random errors are removed and further corrections are applied: e.g. changes in instrumentation and station displacement to new locations. However, temperature acquisitions from GSOD are affected by missing data, therefore preventing the computation of the HWMI and CWMI which need a daily time series of at least 30 years. For this reason, the stations with records of less than 30 years and time series

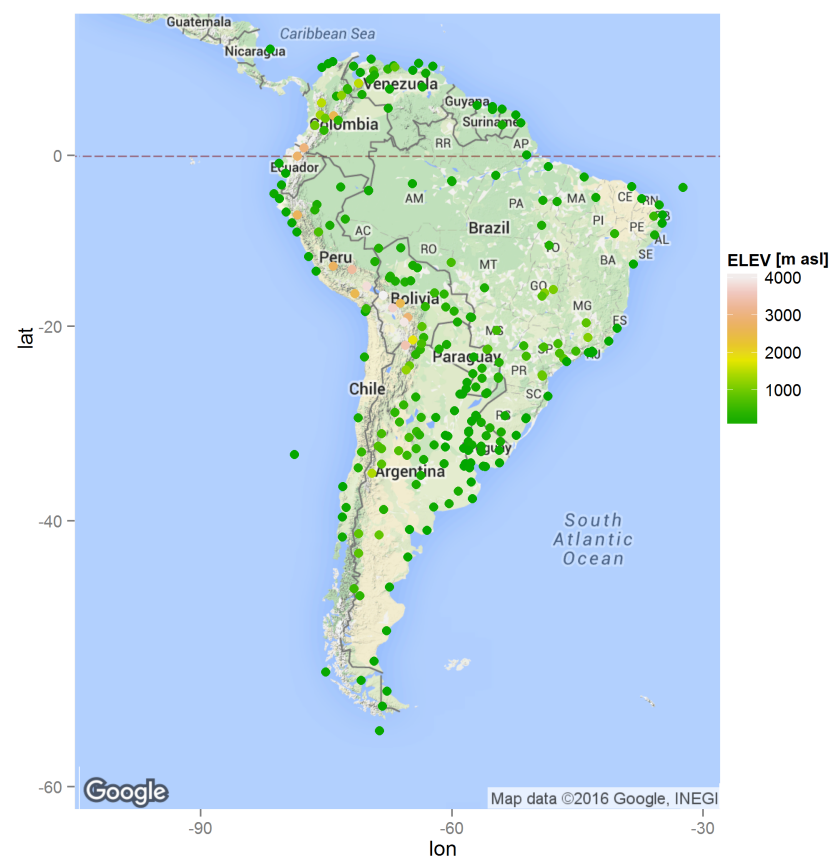

Figure 1. Spatial distribution of temperature gauges used in this study. The colour of the GSOD stations refers to the elevation, expressed in ma.s.l.

with more than $30 \%$ gaps have not been considered in our data record.

Note that a time series with $30 \%$ gaps does not hinder the HWMI and CWMI retrieval, and using that threshold we already exclude $\sim 72 \%$ of the GSOD stations (i.e. 658 out of 912). A further decrease in that threshold will reduce excessively the number of available temperature stations. Figure 1 shows the spatial distribution of the 254 temperature stations that satisfy these conditions with the relative elevation.

\subsubsection{The heat and cold wave magnitude indices}

Before the introduction of the HWMI (Russo et al., 2014), there was no consensus among researchers on the definition of heat waves (Perkins and Alexander, 2012). In fact, most of them take into account only partial aspects of the heat wave event such as maximum temperature, duration, or frequency, without considering the broader picture.

Recently, Russo et al. (2014) have introduced the HWMI able to overcome the limitation above by merging a few climate measures, as duration and temperature anomalies, into a single numerical index (Hoag, 2014). Basically, the magnitude index sums the probability scores associated to consecutive daily temperatures above a threshold (for further details see Russo et al., 2014). The HWMI is a normalized index and therefore it automatically removes the effect of the different elevations of GSOD stations. The HWMI computations require a 30-year time series of daily temperature records; the 
latter normally refers to the 1981-2010 timespan, taken as reference period.

Because of the lack of agreement on a cold wave definition, Forzieri et al. (2015) have recently introduced the CWMI. The CWMI is computed in a similar way to the HWMI, merging the duration and the intensity of the extreme event into a single numerical index.

In this work, both HWMI and CWMI indices are computed to detect South American heat and cold waves in the present climate. For further details on HWMI computation, see the relative definition in Russo et al. (2014). Regarding the CWMI, it has been defined for each GSOD station by the following steps.

1. Daily threshold: for each day of the year, we define the daily threshold as the 10th percentile of the daily temperatures, centred on a 31-day window for the 30-year reference period 1981-2010.

2. Cold wave selection: for each year, we select all the cold waves with at least 3 consecutive days below the daily thresholds.

3. Cold wave to sub-cold waves: we decompose each cold wave into $x$ subcold waves, where a sub-cold wave is a 3-day cold wave.

4. Sub-cold wave unscaled magnitude: for each sub-cold wave, we define the unscaled magnitude as the sum of the (three) daily temperatures.

5. Sub-cold wave scaled magnitude: for each sub-cold wave, we convert the unscaled magnitude to a probability ranging from 0 to 1 , i.e. the scaled magnitude.

6. Cold wave magnitude: we define the magnitude of each cold wave as the sum of the scaled magnitudes of the $x$ subcold waves.

7. Cold Wave Magnitude Index: we define the CWMI for each year as the minimum of all cold wave magnitudes.

Both indices are computed using (1) maximum daily temperature (hereafter $\mathrm{HWMI}_{t x}$ and $\mathrm{CWMI}_{t x}$ ) and (2) minimum daily temperature (hereafter $\mathrm{HWMI}_{t n} \mathrm{CWMI}_{t n}$ ), giving complementary information on warm and cold day and night conditions respectively. Heat and cold wave magnitude indices have been computed on an annual basis for each GSOD station across South America for the period 1980-2014.

Since heat waves generally occur between December and January in the Southern Hemisphere (i.e. throughout the vast majority of South America), the calendar year used for HWMI starts in July and ends in June. This way we avoid splitting heat waves that are likely to happen at the end of December and the beginning of January in two. Therefore, the HWMI computation starts on 1 July 1980 and ends on 30 June 2015. Because of this 6-month "shift" we will refer
Table 1. Classification of heat and cold wave (i.e. HWMI and CWMI) scale categories.

\begin{tabular}{lll}
\hline Classification & $\begin{array}{l}\text { Heat Wave } \\
\text { Magnitude Index }\end{array}$ & $\begin{array}{l}\text { Cold Wave } \\
\text { Magnitude Index }\end{array}$ \\
\hline Normal & $1 \leq \mathrm{HWMI}<2$ & $-1 \geq \mathrm{CWMI}>-2$ \\
Moderate & $2 \leq \mathrm{HWMI}<3$ & $-2 \geq \mathrm{CWMI}>-3$ \\
Severe & $3 \leq \mathrm{HWMI}<4$ & $-3 \geq \mathrm{CWMI}>-4$ \\
Extreme & $4 \leq \mathrm{HWMI}<8$ & $-4 \geq \mathrm{CWMI}>-8$ \\
Very extreme & $8 \leq \mathrm{HWMI}<16$ & $-8 \geq \mathrm{CWMI}>-16$ \\
Super extreme & $16 \leq \mathrm{HWMI}<32$ & $-16 \geq \mathrm{CWMI}>-32$ \\
Ultra extreme & $\mathrm{HWMI} \geq 32$ & $\mathrm{CWMI} \leq-32$ \\
\hline
\end{tabular}

- for heat waves - to 2014 as the year starting on July 2014 and ending on June 2015, and so on.

Conversely, since cold wave events are more likely to happen in the Southern Hemisphere between June and August, the calendar year used for CWMI computation starts in 1 January 1980 and ends in 31 December 2014.

Heat wave and cold wave scale categories are defined with the classes set out in Table 1, following the scheme proposed by Russo et al. (2014) for heat waves. Note that the classification scheme for cold waves traces the one for heat waves, with negative values instead.

\subsubsection{Trend of mean temperature range}

Trend analysis has been carried out for each GSOD station applying the Mann-Kendall test to the time series of annual mean of daily maximum $\left(T_{x}\right)$, daily minimum $\left(T_{n}\right)$, and MTR. MTR is the difference between the annual mean of the daily maximum temperature and the annual mean of the daily minimum temperature.

Note that the intermittent nature of heat and cold waves and the abrupt change in the last 10 years (see Sect. 3.1) prevent us from carrying out a trend analysis for HWMI and CWMI using non-stationary peak over threshold models or other kinds of trend analysis (for further information, annual values of both HWMI and CWMI are available in the Supplement).

MTR spans the high-temperature events of the summer season and the low-temperature events of the winter season. If the minimum temperature increases faster (slower) than the maximum, the temperature distribution becomes narrower (wider). Thus changes in MTR are mainly related to changes in the width of the average temperature distribution.

The Mann-Kendall trend test (Mann, 1945) allows us to detect significant trends in time series of temperatures without assuming any particular distribution. The Mann-Kendall test statistically assesses whether there is a positive or negative trend over time. As the test is non-parametric, it is less conditioned by outliers. 


\section{HWMItx 1980-1984 HWMItx 1985-1989 HWMItx 1990-1994 HWMItx 1995-1999}
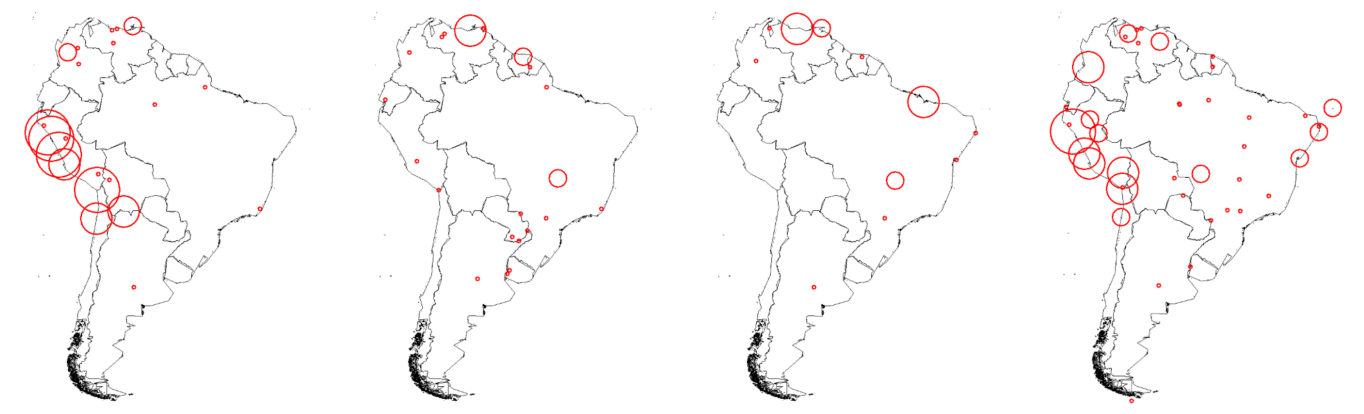

HWMItx 2000-2004 HWMItx 2005-2009 HWMItx 2010-2014
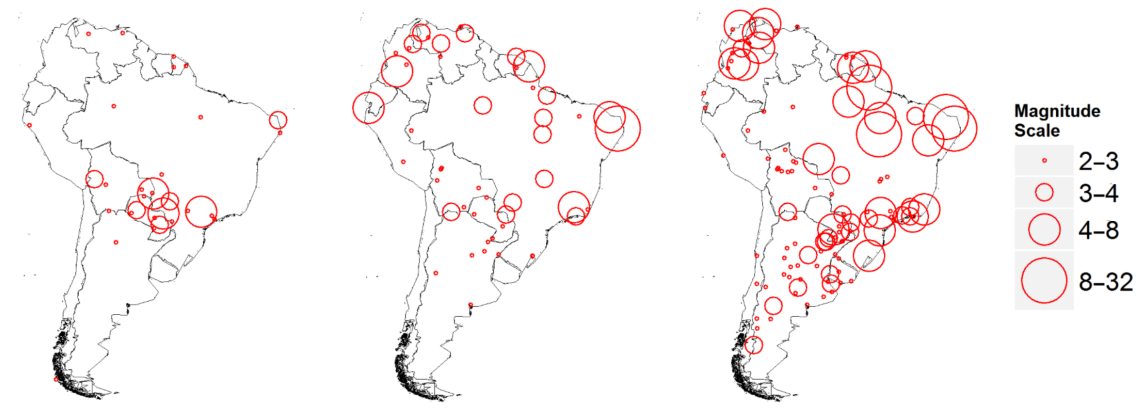

Figure 2. Heat Wave Magnitude Index of maximum temperatures $\left(\mathrm{HWMI}_{t x}\right)$ for 5-year periods from 1980 to 2014 . The magnitude scale follows the classification of heat waves provided in Table 1.

\section{Results}

\subsection{Heat wave}

Figure 2 shows the maximum value in 5-year periods of the $\mathrm{HWMI}_{t x}$ from 1980 to 2014. Four magnitude classes are shown. Since the magnitude class $16-32$ occurs only three times, it has been merged with the class $8-16$ for the sake of clarity. Considering that maximum and minimum temperature are highly correlated, results with $\mathrm{HWMI}_{t n}$ do not differ significantly from those detected with $\mathrm{HWMI}_{t x}$ (see Supplement).

There is evidence that an increase of heat wave intensity is ongoing. Specifically, from 1995 onwards it is possible to observe heat waves spread across South America, with the maximum presence during 2010-2014. Between 1980 and 1984 there have been heat waves with magnitude equal to 16 across the central part of the continent, mainly corresponding to Peru, whereas other regions do not show such great heat waves (for further details see the Supplement). In particular, in the austral summer of 1982-1983, during one of the strongest El Niño events (Cane, 1983) of the 20th century, the highest HWMI values in Peru were comparable with the HWMI peak of the 2003 European heat wave that killed more than 70000 people (Robine et al., 2008; Russo et al., 2014).
The central part of the continent also displays severe heat waves during 1995-1999 in correspondence with the 199798 El Niño event (McPhaden, 1999), whereas the rest of the region does not present patterns related to El Niño. Generally, HWMI's frequency is low until 1994 and then increases rapidly.

Histograms in Fig. 3 show the temporal distribution of heat wave for each class of magnitude for both maximum temperature $\left(T_{x}\right.$, upper panel) and minimum temperature $\left(T_{n}\right.$, bottom panel). The 5-year time window allows us to better visualize the evolution of heat waves and to filter out the influence of El Niño on the occurrence of extreme events. Results complement and confirm previous findings shown in Fig. 2. The occurrence of heat waves generally increased in the last 10 years. This is noticeable from the analysis of the histograms, where the occurrence of heat waves rises from $20(20)$ to 150 (50) heat wave events per 5-year period for maximum (minimum) temperature from 1980-1984 to 2010-2014. Also, our results show that $35 \%$ of the available meteorological stations present intense heat waves with $\operatorname{HWMI}_{t x} \geq 2$.

Maximum temperature shows the highest number of heat waves, while minimum temperature shows the lowest. For maximum temperature, the increase in heat wave events occurred for all the magnitude classes. For minimum temperature it is possible to observe the upward trend only for 


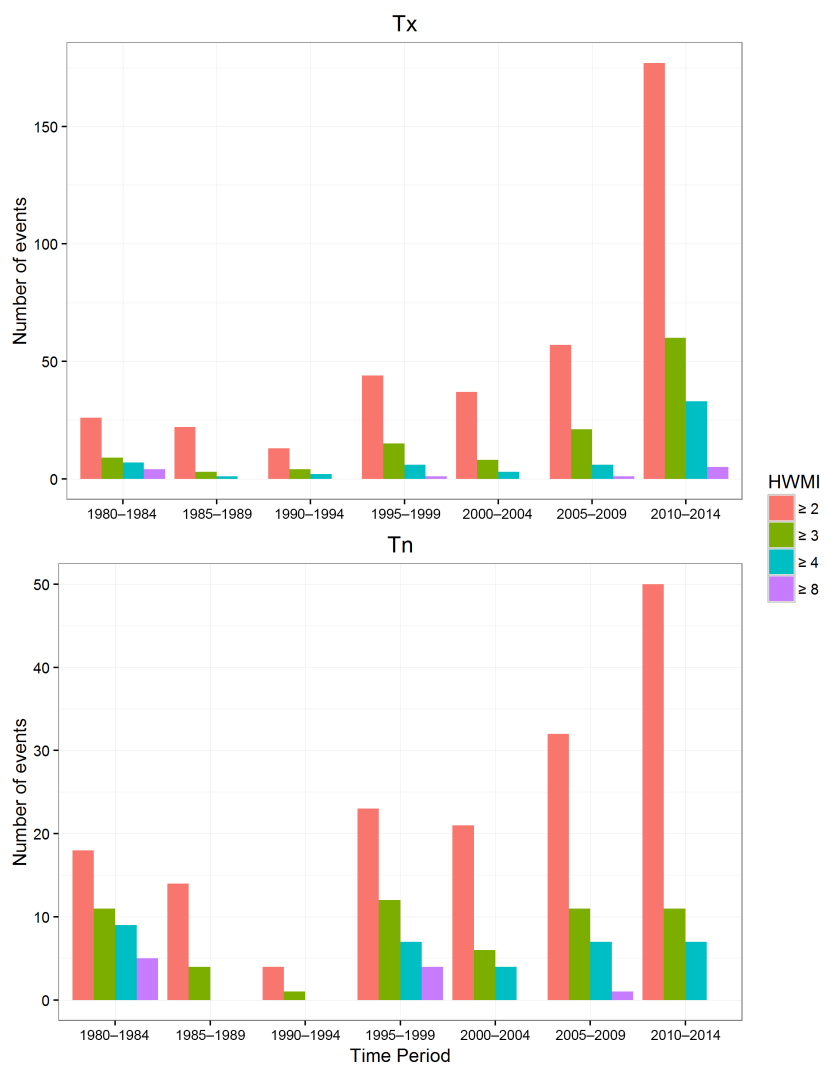

Figure 3. Histogram of heat waves for 5-year periods during 19802014 for maximum temperature ( $T_{x}$, upper panel) and minimum temperature $\left(T_{n}\right.$, bottom panel).

heat waves with magnitude greater than 2, whereas the other classes are relatively stationary. Between 2005 and 2014 the frequency of extreme heat waves has increased to 40 observations per year, as compared to $\sim 8.5$ per year in the period from 1980 to 2004.

Maximum temperature has the highest number of heat waves, with 1805 occurrences, while minimum temperature has the lowest, with 1025 occurrences. Note that this tally includes heat waves with HWMI greater than 1 (i.e. "normal" heat waves) that are not shown in Figs. 2 and 3.

Annual maps of $\mathrm{HWMI}_{t x}$ and $\mathrm{CWMI}_{t n}$ are provided in the Supplement. By way of example, Fig. 4 shows the HWMI $t x$ for 2013 when Argentina, Uruguay, and Brazil experienced intense heat waves. Specifically, Argentina and Uruguay experienced extremely warm temperatures at the end of 2013 (Blunden and Arndt, 2014), whereas the cities of Sao Paulo and Rio de Janeiro (south-eastern Brazil) experienced their warmest January and February at the beginning of 2014 (Blunden and Arndt, 2015). Note that 2013 refers to the period July 2013-June 2014, as explained in the method section. GSOD-derived observations are able to capture and quantify extreme weather events that occurred between 2013 and 2014. The spatial distribution of the HWMI also shows
HWMItx2013

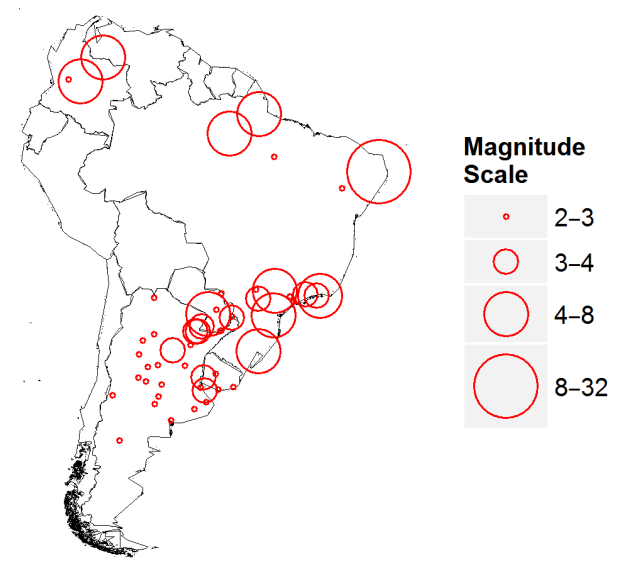

Figure 4. Heat Wave Magnitude Index of maximum temperature $\left(\mathrm{HWMI}_{t x}\right)$ for 2013 .

a hot spot of increase in HWMI frequency and magnitude from 2009 onwards across Paraguay and south-eastern Brazil, as shown in Fig. S3 of the Supplement. However, spatial patterns of heat waves are heavily influenced by the distribution of GSOD stations throughout the continent.

\subsection{Cold wave}

As for heat waves, Fig. 5 shows the $\mathrm{CWMI}_{t n}$ for 5 -year periods from 1980 to 2014 (5-year maps for $\mathrm{CWMI}_{t x}$ are shown in the Supplement). By means of the CWMI we were able to detect the strongest cold waves occurred in Latin America since 1980. It is possible to see that the vast majority of cold waves have a moderate magnitude with CWMI not below -3. Contrary to HWMI, it is not possible to distinguish an increase of cold wave intensity in the last decade.

Very extreme cold waves (i.e. CWMI $\leq-8$ ) are detected in correspondence to $1980-1984$ and $1995-1999$ periods across Ecuador and Venezuela. However, there is no temporal coherence with El Niño events (i.e. 1982-1983 and 1997-1998), since the major cold wave events took place during 1980 and 1996 respectively (annual maps of CWMI ${ }_{t n}$ are shown in the Supplement).

Just as for heat waves, histograms in Fig. 6 show the temporal distribution of cold waves for each class of magnitude.

The occurrence of cold waves is essentially stationary across the weather stations. Only $\mathrm{CWMI}_{t n} \leq-2$ and $\leq-3$ exhibit a positive trend in the 1980-1999 period, with a peak during 1995-1999 and a negative trend afterwards. Specifically, GSOD stations with $\mathrm{CWMI}_{t n} \leq-2$ are nearly double the number of the other periods.

Differently from heat waves, the CWMI applied to minimum and maximum temperatures has the same order of occurrence, with 1150 and 1187 events respectively. Cold 
CWMItn 1980-1984

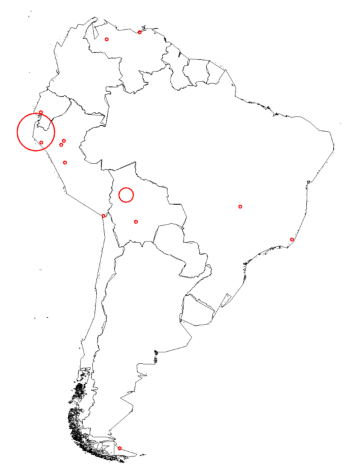

CWMItn 2000-2004

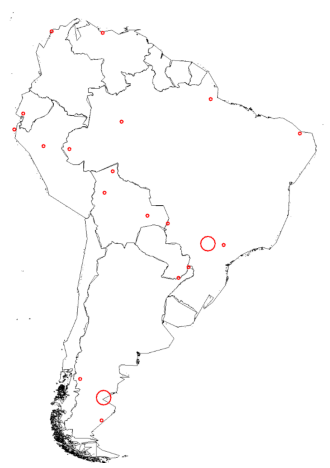

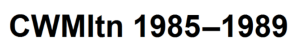

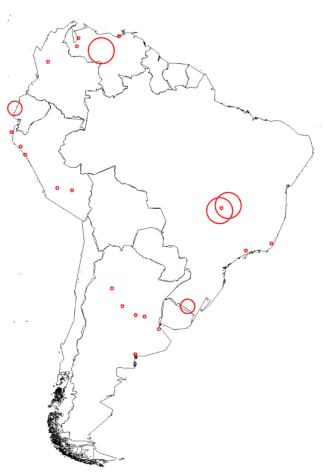

CWMItn 2005-2009

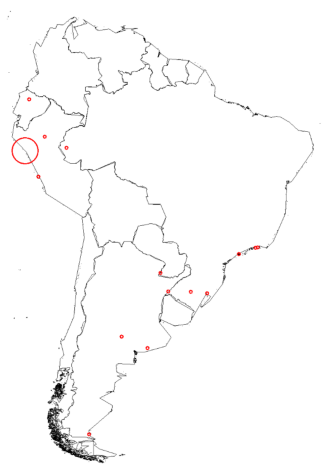

CWMItn 1990-1994

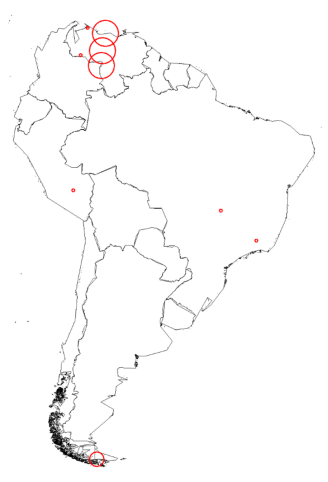

CWMItn 1995-1999

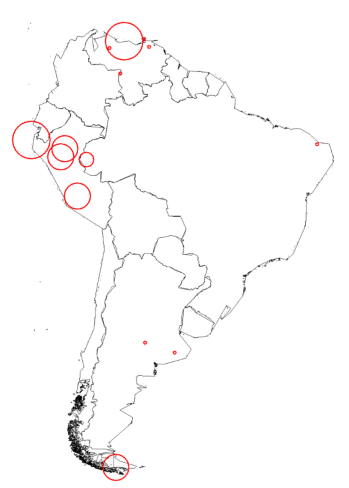

CWMItn 2010-2014

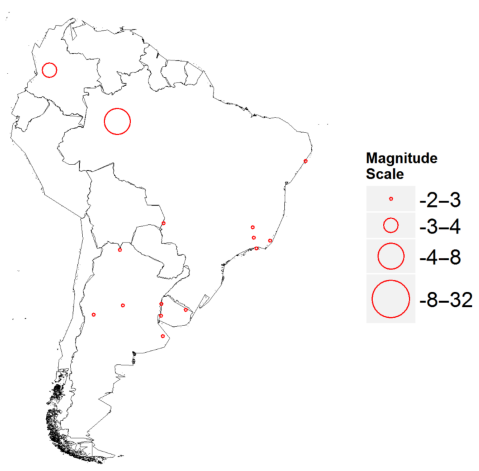

Figure 5. Cold Wave Magnitude Index of minimum temperature $\left(\mathrm{CWMI}_{t n}\right)$ for 5-year periods from 1980 to 2014 . The magnitude scale follows the classification of cold waves provided in Table 1.

waves with CWMI $\leq-2$ are observed for $32 \%$ of the available GSOD stations (i.e. about 83 stations).

\subsection{Trend analysis}

Figure 7 shows the slope of statistically significant trends, if any, of (1) annual mean of daily maximum temperature, (2) annual mean of daily minimum temperature, and (3) MTR. Note that only stations with a statistically significant trend (i.e. $p$ value smaller than 0.05 , or $5 \%$ ) are shown, and the number of points changes accordingly. Interestingly, MTR displays trends in stations where there are no trends for either minimum or maximum temperature.

Annual mean of daily maximum temperature is generally increasing - up to $1{ }^{\circ} \mathrm{C}$ per decade - across the continent; only a few stations display a negative trend. Annual mean of daily minimum temperature is increasing (up to $1{ }^{\circ} \mathrm{C}$ per decade) in the tropics (i.e. above $-23^{\circ} \mathrm{N}$ ) and decreasing (up to $0.5^{\circ} \mathrm{C}$ per decade) in the extratropics. MTR displays a widening behaviour in the extratropics, where the temperature range displays a broadening trend of up to $1^{\circ} \mathrm{C}$ per decade. Conversely, spatial patterns of MTR trends in the tropics indicate that negative trends generally prevail, with a few stations erratically showing positive trends. However, both spatial density and magnitude of negative trend across the tropics are less prominent than the positive ones in the south. The maximum reduction found in MTR is equal to $0.5^{\circ} \mathrm{C}$ per decade.

The number of GSOD stations that display statistical significant trends for maximum temperature, minimum temperature, or MTR (i.e. all the stations shown in Fig. 7) is equal to 75 .

\subsection{Extreme temperatures over a megacity: Bogota}

In order to confirm our previous findings, the daily meteorological data pertaining to the Bogota have been analysed. Located in the tropics, Bogota and its metropolitan area is one of the four megacities of South America and represents one of the areas more at risk of extreme events (Instituto de Hidrología, Meteorología y Estudios Ambientales et al., 2014). The meteorological station is located in the El Dorado International Airport, $15 \mathrm{~km}$ north-west of central Bogota.

Figures 8 and 9 show the 10-day moving average of daily maximum and minimum temperatures respectively. The average values (i.e. mean $\pm 2 \mathrm{SD}$ - standard deviation) of the 1980-2014 time series are in dark brown and the highest and lowest values in light brown. 

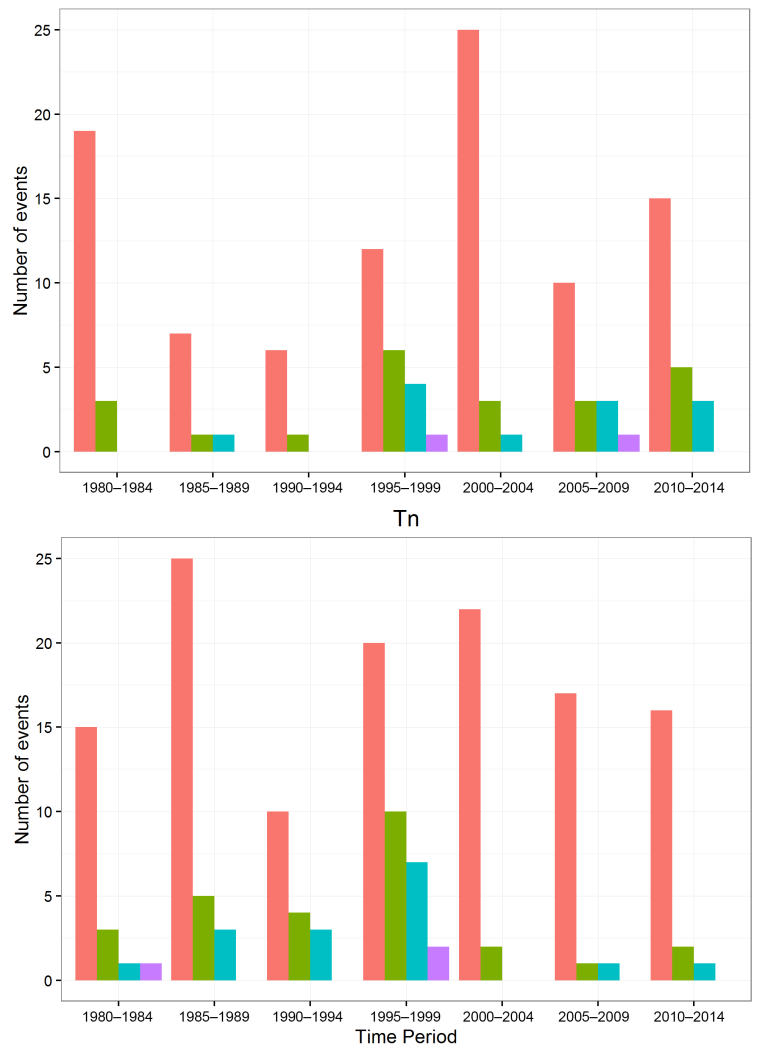

Figure 6. Histogram of cold waves for 5-year periods during 19802014 for maximum temperature ( $T_{x}$, upper panel) and minimum temperature $\left(T_{n}\right.$, bottom panel).

The black lines in Figs. 8 and 9 represent the 10-day moving average of daily average for 1980-2014 of maximum and minimum temperature respectively.

Similarly, the orange lines represent the 10-day moving average of daily average in the most recent 5 -year period (i.e. 2010-2014).

In the last 5 years our data show a shift towards warmer temperatures: in 2010-2014 temperature values are nearly always above the 1980-2014 average. This is particularly noticeable for minimum temperatures, upholding what we previously found across the tropics: $T_{n}$ is increasing faster than $T_{x}$.

The two-sample Kolmogorov-Smirnov test has been employed to test whether daily average for 2010-2014 and daily average for 1980-2014 come from the same distribution, for both maximum and minimum temperature.

The $p$ value has been calculated, getting the result of $1.14 \times 10^{-9}$ and $1.82 \times 10^{-5}$ for maximum and minimum temperature respectively. With a so low $p$ value, it is reasonable to assume that they do not come from the same distribution. The null hypothesis is rejected and we can infer that different statistical distributions are indeed present, thereby confirming our graphical inference.

\section{Discussion}

Our work is as an attempt towards temperature regime characterization of South America and presents a number of caveats thereof.

Firstly, the spatial distribution of GSOD station is a critical aspect. GSOD stations are unevenly distributed across the region. In addition, as heat/cold waves do not occur homogeneously throughout all of South America, the location of the observing stations surely influences the results. However, spatial distribution of temperature, especially at daily level, is a major issue for this region with such a sparse network. Definitively, the GSOD data set represents the state of the art of daily temperature records across South America where large gaps exist (e.g. records were interrupted or stations were removed). This is of course an issue that cannot be rectified, and only reanalysis products might help in producing consistent pictures of the region.

Secondly, it is likely that land use changes such as urbanization or large agricultural expansion induce abrupt changes or jumps in the time series of temperature (Zhou et al., 2014), and these aspects has not been taken into account in our study. However, trends and abrupt changes cannot be easily distinguished in statistical tests (Yevjevich, 1987) since they are very closely intertwined.

Thirdly, trend analysis presented in this study cannot predict future climate patterns completely accurately. Caution should be exercised: evidence from longer records, instrumental or proxy, suggests that local trends are omnipresent but not monotonic; rather, at some time upward trends turn to downward ones and vice versa (Montanari and Koutsoyiannis, 2014).

Fourthly, the location of the meteorological stations can certainly affect the temperatures recorded. GSOD records, which often pertain to urban areas, are subject to the urban island effect that influences the recorded surface air temperatures, as shown across the USA by Fall et al. (2011) and at global scale by Kalnay and Cai (2003).

That being said, our analysis provides a unique research opportunity to explore observed extreme temperature regimes across South America, reducing spatial and temporal gaps on heat and cold waves and their trends (Perkins, 2015). This analysis takes advantage of the state-of-the-art technique developed in heat wave (Hoag, 2014) and cold wave (Forzieri et al., 2015) assessment. This analysis gives a perspective on cold waves, which have been rarely studied.

There is evidence of an ongoing increase in intensity and frequency of heat wave events. Specifically, from 1995 onwards it is possible to observe heat wave spread with the maximum presence during 2010-2014. In the last 10 years (i.e. 2005-2014), the number of GSOD stations that experienced heat waves is greater than in the previous 25-year period (i.e. 1980-2004). Interestingly, the spatial patterns of heat waves across Peru display a correspondence with El 

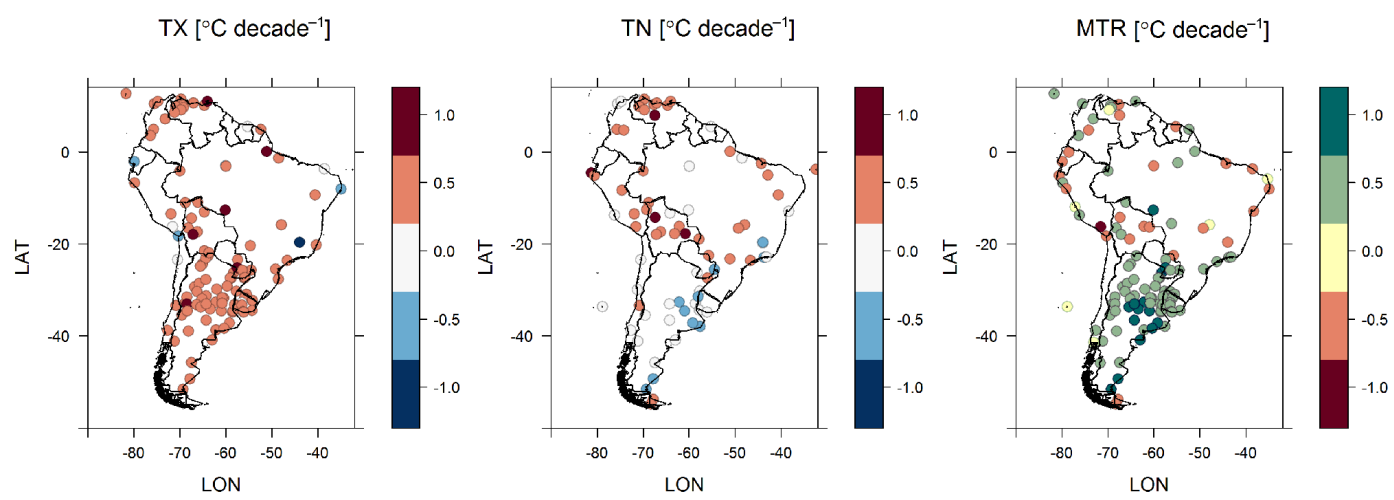

Figure 7. Trend in the mean annual maximum temperature $\left(T_{t}\right.$, left panel), mean annual minimum temperature $\left(T_{n}\right.$, central panel), and mean temperature range (MTR, right panel). Units are expressed in Celsius degrees per decade $\left[{ }^{\circ} \mathrm{C}\right.$ decade $\left.{ }^{-1}\right] . T_{x}$ and $T_{t}$ have the same colour bar.

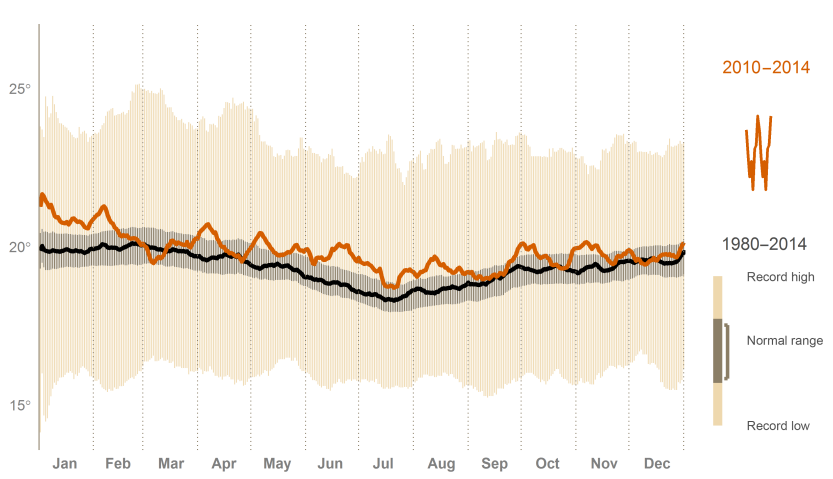

Figure 8. Bogota 10-day moving average of maximum daily temperature (2010-2014 versus 1980-2014 values).

Niño events (Carmona-Moreno et al., 2005), whereas the rest of the continent does not show such great similarities.

Maximum temperature displays the highest number of heat waves and minimum temperature the lowest. Interestingly, the HWMI applied to minimum temperature displays lower magnitude than the HWMI values calculated with daily maximum; there are no evident trends in the temporal distribution of heat waves with magnitude index greater than 3 . This might be due to the rapid night-time cooling, especially along the ocean coastline.

The occurrence of cold wave is essentially stationary in the sense of both intensity and frequency, with the exception of minimum temperature. In this regard, it is possible to observe an upward trend, with the peak between 1995 and 1999, turning downwards afterwards. Specifically, the number of GSOD stations with CWMI less or equal to -2 during 19952000 is twice the number of events during the other periods. Cold waves do not display temporal coherence with El Niño events. Apparently, there are no similarities between $\mathrm{La}$ Niña events, volcanic eruptions, such as the Pinatubo eruption of 1991, and cold waves across South America.

Annual mean of daily maximum temperature is generally increasing, up to $1^{\circ} \mathrm{C}$ per decade, whereas annual mean

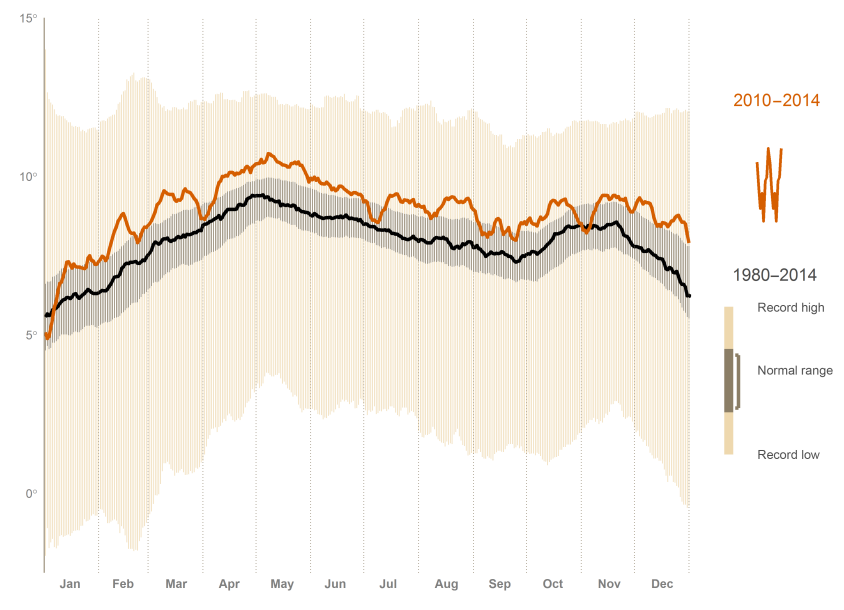

Figure 9. Bogota 10-day moving average of minimum daily temperature (2010-2014 versus 1980-2014 values).

of daily minimum temperature is increasing (up to $1{ }^{\circ} \mathrm{C}$ per decade) in the tropics and decreasing (up to $0.5^{\circ} \mathrm{C}$ per decade) in the extratropics. Also, MTR displays an opposed latitude-dependent behaviour. MTR shows a broadening trend up to $1^{\circ} \mathrm{C}$ per decade in the extratropics, while negative trends generally prevail in the tropics, with a reduction up to $0.5^{\circ} \mathrm{C}$ per decade. Generally, minimum temperature shows interannual variability higher than maximum temperature, as shown in Figs. 8 and 9. This effect might hinder the trend detection of minimum temperature, especially when the relative trend is included in the range of variability.

Results support the findings of Mishra et al. (2015): the number of heat waves has increased. The occurrence of heat waves with a magnitude index greater than 2 has been most prominent in the most recent period. Results also support what was reported in Kenyon and Hegerl (2008): temperature extremes are substantially affected by El Niño.

Generally, there is agreement with Rusticucci (2012) on the positive trends of warm night (i.e. heat waves of mini- 
mum temperature), even if the trend of heat waves related to maximum temperature is more pronounced.

Finally, coherence with IPCC 2007 findings (Solomon et al., 2007) has been examined. The IPCC theoretical prediction for increasing in maximum temperature are coherent with our results. Conversely, in our study the dramatic rise of daily minimum temperatures, projected to increase faster than daily maximum temperatures, has been found only over the tropics.

\section{Conclusions}

This study assesses the specific behaviour of extreme temperature regimes from the GSOD database recorded across South America in the period 1980-2014. Analysis of the extreme values and trends of interannual ranges of temperatures are crucial since it gives insight into "outside-of-the-box" scenarios (Lagadec, 2004) which very few studies consider. Applications of these analyses are manifold in essential sectors such as local health and social care systems (Carmichael et al., 2012; Gupta and Gregg, 2012).

Heat and cold waves are calculated using the Heat Wave Magnitude Index (Russo et al., 2014) and the Cold Wave Magnitude Index obtained by adapting the HWMI as an equivalent indicator, for maximum and minimum daily temperatures. Finally, trend detection has been performed to assess the significance of temporal changes in the annual mean of daily maximum temperature, annual mean of daily minimum temperature, and the MTR.

Results from heat wave analysis indicates the presence of an increase in intensity and in frequency of extreme events in the last 10 years. Results from cold wave analysis show an erratic behaviour and no conclusion can be drawn. Heat wave shows temporal coherence with El Niño events (i.e. 19821983 and 1997-1998), whereas no connection between cold waves and El Niño can be inferred from our analysis.

MTR trends indicate that the maximum temperature is generally increasing faster than the minimum temperature over the extratropics. Across the tropics, the interannual ranges of mean temperature are generally narrowing, even if the corresponding spatial patterns are not outstandingly noticeable.

The outcomes described in this paper open the possibility to extend the presented scheme over very long periods worldwide. Further applications include the study of the impact of land use changes on heat waves and differential increases in temperature. Other applications of the paper include the employment of GSOD records as an independent check that temperature reconstructions produced using reanalysis data such as ERA-INTERIM (Dee et al., 2011) are in line with raw data from observational stations.

\section{The Supplement related to this article is available online} at doi:10.5194/nhess-16-821-2016-supplement.
Acknowledgements. Authors would like to thank the valuable support from JRC. This work has received funding from European Commission EuropeAid Co-operation Office under grant agreements EUROCLIMA and RALCEA. The data used in this manuscript can be obtained from Global Summary of the Day (GSOD) version 8, National Climatic Data Center (ftp://ftp.ncdc.noaa.gov/pub/data/gsod/). The code used to produce Bogota's daily temperature graphic has been provided by http://rpubs.com/bradleyboehmke/weather_graphic. Heat and cold wave magnitude indices have been computed using the $\mathrm{R}$ library "extRemes" (Gilleland, 2015). Google data are registered trademarks of Google Inc., used with permission. The authors acknowledge Hugh Eva for his invaluable help for editing the paper and the two reviewers for their fruitful comments.

Edited by: R. Trigo

Reviewed by: D. Lee and one anonymous referee

\section{References}

Barnett, A. G., Hajat, S., Gasparrini, A. and Rocklöv, J.: Cold and heat waves in the United States, Environ. Res., 112, 218-224, doi:10.1016/j.envres.2011.12.010, 2012.

Beniston, M.: The 2003 heat wave in Europe: A shape of things to come? An analysis based on Swiss climatological data and model simulations, Geophys. Res. Lett., 31, L02202, doi:10.1029/2003GL018857, 2004.

Blunden, J. and Arndt, D. S.: State of the Climate in 2013, B. Am. Meteorol. Soc., 95, S1-S279, doi:10.1175/2014BAMSStateoftheClimate.1, 2014.

Blunden, J. and Arndt, D. S.: State of the Climate in 2014, B. Am. Meteorol. Soc., 96, ES1-ES32, doi:10.1175/2015BAMSStateoftheClimate.1, 2015.

Cane, M. A.: Oceanographic Events during El Niño, Science, 222, 1189-1195, 1983.

Carmichael, C., Bickler, G., Kovats, S., Pencheon, D., Murray, V., West, C., and Doyle, Y.: Overheating and Hospitals - What do we know?, J. Hosp. Adm., 2, 1-7, doi:10.5430/jha.v2n1p1, 2012.

Carmona-Moreno, C., Belward, A., Malingreau, J.-P., Hartley, A., Garcia-Alegre, M., Antonovskiy, M., Buchshtaber, V., and Pivovarov, V.: Characterizing interannual variations in global fire calendar using data from Earth observing satellites, Global Change Biol., 11, 1537-1555, doi:10.1111/j.1365-2486.2005.01003.x, 2005.

Conti, S., Meli, P., Minelli, G., Solimini, R., Toccaceli, V., Vichi, M., Beltrano, C., and Perini, L.: Epidemiologic study of mortality during the Summer 2003 heat wave in Italy, Environ. Res., 98, 390-399, doi:10.1016/j.envres.2004.10.009, 2005.

Dee, D. P., Uppala, S. M., Simmons, A. J., Berrisford, P., Poli, P., Kobayashi, S., Andrae, U., Balmaseda, M. A., Balsamo, G., Bauer, P., Bechtold, P., Beljaars, A. C. M., van de Berg, L., Bidlot, J., Bormann, N., Delsol, C., Dragani, R., Fuentes, M., Geer, A. J., Haimberger, L., Healy, S. B., Hersbach, H., Hólm, E. V., Isaksen, L., Kållberg, P., Köhler, M., Matricardi, M., McNally, A. P., Monge-Sanz, B. M., Morcrette, J.-J., Park, B.-K., Peubey, C., de Rosnay, P., Tavolato, C., Thépaut, J.-N., and Vitart, F.: The ERA-Interim reanalysis: configuration and performance of the 
data assimilation system, Q. J. Roy. Meteorol. Soc., 137, 553597, doi:10.1002/qj.828, 2011.

Fall, S., Watts, A., Nielsen-Gammon, J., Jones, E., Niyogi, D., Christy, J. R., and Pielke, R. A.: Analysis of the impacts of station exposure on the U.S. Historical Climatology Network temperatures and temperature trends, J. Geophys. Res.-Atmos., 116, D14120, doi:10.1029/2010JD015146, 2011.

Field, C. B., Barros, V., Stocker, T. F., and Dahe, Q.: Managing the Risks of Extreme Events and Disasters to Advance Climate Change Adaptation: Special Report of the Intergovernmental Panel on Climate Change, Cambridge University Press, Cambridge, UK, available at: https://books.google.it/books?id= BL6ouAAACAAJ (last access: November 2015), 2012.

Forzieri, G., Feyen, L., Russo, S., Vousdoukas, M., Alfieri, L., Outten, S., Migliavacca, M., Bianchi, A., Rojas, R., and Cid, A.: Multi-hazard assessment in Europe under climate change, Climatic Change, accepted, 2015.

Gilleland, E.: extRemes: Extreme Value Analysis, available at: https://cran.r-project.org/web/packages/extRemes/index.html, last access: 9 September 2015.

Gupta, R. and Gregg, M.: Using UK climate change projections to adapt existing English homes for a warming climate, Build. Environ., 55, 20-42, doi:10.1016/j.buildenv.2012.01.014, 2012.

Hoag, H.: Russian summer tops "universal" heatwave index, Nature News October 2014, doi:10.1038/nature.2014.16250, 2014.

Instituto de Hidrología, Meteorología y Estudios Ambientales, IDEAM, DNP, MADS, Parques Nacionales Naturales de Colombia, Instituto Humboldt, Corpoguavio, Gobernación de Cundinamarca, CAR, Alcaldía de Bogotá and PNUD, Bogota and Cundinamarca Face to Climate Change: Strategy Summary and Main Results of the Proces, PNUD, Bogotá, 1-79, 2014.

Kalnay, E. and Cai, M.: Impact of urbanization and land-use change on climate, Nature, 423, 528-531, doi:10.1038/nature01675, 2003.

Kenyon, J. and Hegerl, G. C.: Influence of Modes of Climate Variability on Global Temperature Extremes, J. Climate, 21, 38723889, doi:10.1175/2008JCLI2125.1, 2008.

Lagadec, P.: Understanding the French 2003 Heat Wave Experience: Beyond the heat, a Multi-Layered Challenge, J. Contingen. Cris. Manage., 12, 160-169, doi:10.1111/j.09660879.2004.00446.x, 2004.

Magrin, G. O., Marengo, J. A., Boulanger, J.-P., Buckeridge, M. S., Castellanos, E., Poveda, G., Scarano, F. R., and Vicuña, S.: Central and South America, in: Climate Change 2014: Impacts, Adaptation, and Vulnerability, Part B: Regional Aspects, Contribution of Working Group II to the Fifth Assessment Report of the Intergovernmental Panel of Climate Change, edited by: Barros, V. R., Field, C. B., Dokken, D. J., Mastrandrea, M. D., Mach, K. J., Bilir, T. E., Chatterjee, M., Ebi, K. L., Estrada, Y. O., Genova, R. C., Girma, B., Kissel, E. S., Levy, A. N., MacCracken, S., Mastrandrea, P. R., and White, L. L., Cambridge University Press, Cambridge, UK and New York, NY, USA, 1499-1566, 2014.

Mann, H. B.: Nonparametric tests against trend, Econometrica, 13, 245-259, 1945.

McPhaden, M. J.: El Niño: The child prodigy of 1997-98, Nature, 398, 559-562, doi:10.1038/19193, 1999.
Mishra, V., Ganguly, A. R., Nijssen, B., and Lettenmaier, D. P.: Changes in observed climate extremes in global urban areas, Environ. Res. Lett., 10, 024005, doi:10.1088/17489326/10/2/024005, 2015.

Montanari, A. and Koutsoyiannis, D.: Modeling and mitigating natural hazards: Stationarity is immortal!, Water Resour. Res., 50, 9748-9756, doi:10.1002/2014WR016092, 2014.

Niang, I., Ruppel, O. C., Abdrabo, M. A., Essel, A., Lennard, C., Padgham, J., and Urquhart, P.: Africa, in: Climate Change 2014: Impacts, Adaptation, and Vulnerability, Part B: Regional Aspects. Contribution of Working Group II to the Fifth Assessment Report of the Intergovernmental Panel of Climate Change, edited by: Barros, V. R., Field, C. B., Dokken, D. J., Mastrandrea, M. D., Mach, K. J., Bilir, T. E., Chatterjee, M., Ebi, K. L., Estrada, Y. O., Genova, R. C., Girma, B., Kissel, E. S., Levy, A. N., MacCracken, S., Mastrandrea, P. R., and White, L. L.: Cambridge University Press, Cambridge, UK and New York, NY, USA, 1199-1265, 2014.

Ostro, B. D., Roth, L. A., Green, R. S., and Basu, R.: Estimating the mortality effect of the July 2006 California heat wave, Environ Res., 109, 614-619, doi:10.1016/j.envres.2009.03.010, 2009.

Pachauri, R. K., Allen, M. R., Barros, V. R., Broome, J., Cramer, W., Christ, R., Church, J. A., Clarke, L., Dahe, Q., Dasgupta, P., Dubash, N. K., Edenhofer, O., Elgizouli, I., Field, C. B., Forster, P., Friedlingstein, P., Fuglestvedt, J., Gomez-Echeverri, L., Hallegatte, S., Hegerl, G., Howden, M., Jiang, K., Jimenez Cisneroz, B., Kattsov, V., Lee, H., Mach, K. J., Marotzke, J., Mastrandrea, M. D., Meyer, L., Minx, J., Mulugetta, Y., O’Brien, K., Oppenheimer, M., Pereira, J. J., Pichs-Madruga, R., Plattner, G.-K., Pörtner, H.-O., Power, S. B., Preston, B., Ravindranath, N. H., Reisinger, A., Riahi, K., Rusticucci, M., Scholes, R., Seyboth, K., Sokona, Y., Stavins, R., Stocker, T. F., Tschakert, P., van Vuuren, D., and van Ypserle, J.-P.: Climate Change 2014: Synthesis Report, in: Contribution of Working Groups I, II and III to the Fifth Assessment Report of the Intergovernmental Panel on Climate Change, available at: http://epic.awi.de/37530/ (last access: 17 March 2015), 2014.

Perkins, S. E.: A review on the scientific understanding of heatwaves - Their measurement, driving mechanisms, and changes at the global scale, Atmos. Res., 164-165, 242-267, doi:10.1016/j.atmosres.2015.05.014, 2015.

Perkins, S. E. and Alexander, L. V.: On the Measurement of Heat Waves, J. Climate, 26, 4500-4517, doi:10.1175/JCLI-D-1200383.1, 2012.

Robine, J.-M., Cheung, S. L. K., Le Roy, S., Van Oyen, H., Griffiths, C., Michel, J.-P., and Herrmann, F. R.: Death toll exceeded 70,000 in Europe during the summer of 2003, C. R. Biol., 331, 171-178, doi:10.1016/j.crvi.2007.12.001, 2008.

Russo, S., Dosio, A., Graversen, R. G., Sillmann, J., Carrao, H., Dunbar, M. B., Singleton, A., Montagna, P., Barbola, P., and Vogt, J. V.: Magnitude of extreme heat waves in present climate and their projection in a warming world, J. Geophys. Res.Atmos., 119, 12500-12512, doi:10.1002/2014JD022098, 2014.

Rusticucci, M.: Observed and simulated variability of extreme temperature events over South America, Atmos. Res., 106, 1-17, doi:10.1016/j.atmosres.2011.11.001, 2012.

Solomon, S.: Intergovernmental Panel on Climate Change, Intergovernmental Panel on Climate Change, and Working Group I: Climate change 2007: the physical science basis: contribution of 
Working Group I to the Fourth Assessment Report of the Intergovernmental Panel on Climate Change, Cambridge University Press, Cambridge, UK, 1-996, 2007.

WHO: WHO - Climate change and health, WHO, available at: http://www.who.int/mediacentre/factsheets/fs266/en/, last access: 20 October 2015.
Yevjevich, V.: Stochastic models in hydrology, Stoch. Hydrol. Hydraul., 1, 17-36, doi:10.1007/BF01543907, 1987.

Zhou, W., Ji, S., Chen, T.-H., Hou, Y., and Zhang, K.: The 2011 heat wave in Greater Houston: Effects of land use on temperature, Environ. Res., 135, 81-87, doi:10.1016/j.envres.2014.08.025, 2014. 